\title{
Stress radiography of the stifle
}

H. van Bree, H. de Rooster, I. Gielen

Department of Medical Imaging \& Small Animal Orthopaedics

Veterinary Faculty

Ghent University

\section{Introduction}

Cruciate ligament injury is a common problem in dogs, and is generally evaluated by physical examination although it is often overlooked at the time of initial injury. The most consistent findings are joint swelling and instability of the stifle. To assess the instability two tests - the cranial drawer test and the tibial compression test - are often used in veterinary practice. Cranial cruciate ligament (CCL) injuries can be difficult to diagnose by these classical clinical tests alone (Robins 1990). Detection of craniocaudal instability may be masked by factors such as muscle tone caused by pain or stress, effusion, torn menisci, or periarticular fibrosis that develops in chronic cases of cruciate disease (Flo \& DeYoung 1978).

A radiograph shows the spatial relationship between the bones at the joint level. The position of the tibia in relation to the femur will be related directly to the status of the supporting ligaments which originate on one bone, and insert on the other (Jacobsen 1978). On a neutral view of a normal canine stifle in $90^{\circ}$ of flexion, the perpendicular on the femoral axis that runs just cranial to the fabellae, will be almost tangential to the caudal projection of the lateral tibial condyle (Meinen \& Verbeek 1980). In a small number of cases, the cranial displacement of the proximal tibia may be visible on a standard lateral radiograph, without any special stresses being applied to the leg during the positioning (Singleton 1957; Pond \& Campbell 1972; Park 1979; Kirby 1993). This particular sign is called 'Cazieux-positive', and always indicates a ruptured CCL (Meinen \& Verbeek 1980). The tibial compression test (Henderson \& Milton 1978) mimics the contraction of the gastrocnemius muscles, whereby, the stifle joint is fully extended. The tip of the index finger of the hand that immobilises the femur rests on the tibial tuberosity, and the hock joint is repeatedly flexed and extended with the other hand. This test is positive when a cranial displacement of the tibial tuberosity can be felt under the index finger of the upper hand. A stress radiographic technique, based on the clinical tibial compression test, has been introduced in an attempt to improve the diagnostic accuracy of clinical evaluation of craniocaudal instability.

Technique and results

A protocol for obtaining a tibial compression radiograph has been designed for dogs. It was developed to measure relative displacement of bony landmarks on paired lateral radiographs (neutral and tibial compression). Briefly, each dog was positioned in lateral recumbency (Figure). A standard lateral radiographic view of the stifle joint was obtained with the joint at $90^{\circ}$ of flexion (neutral position). 

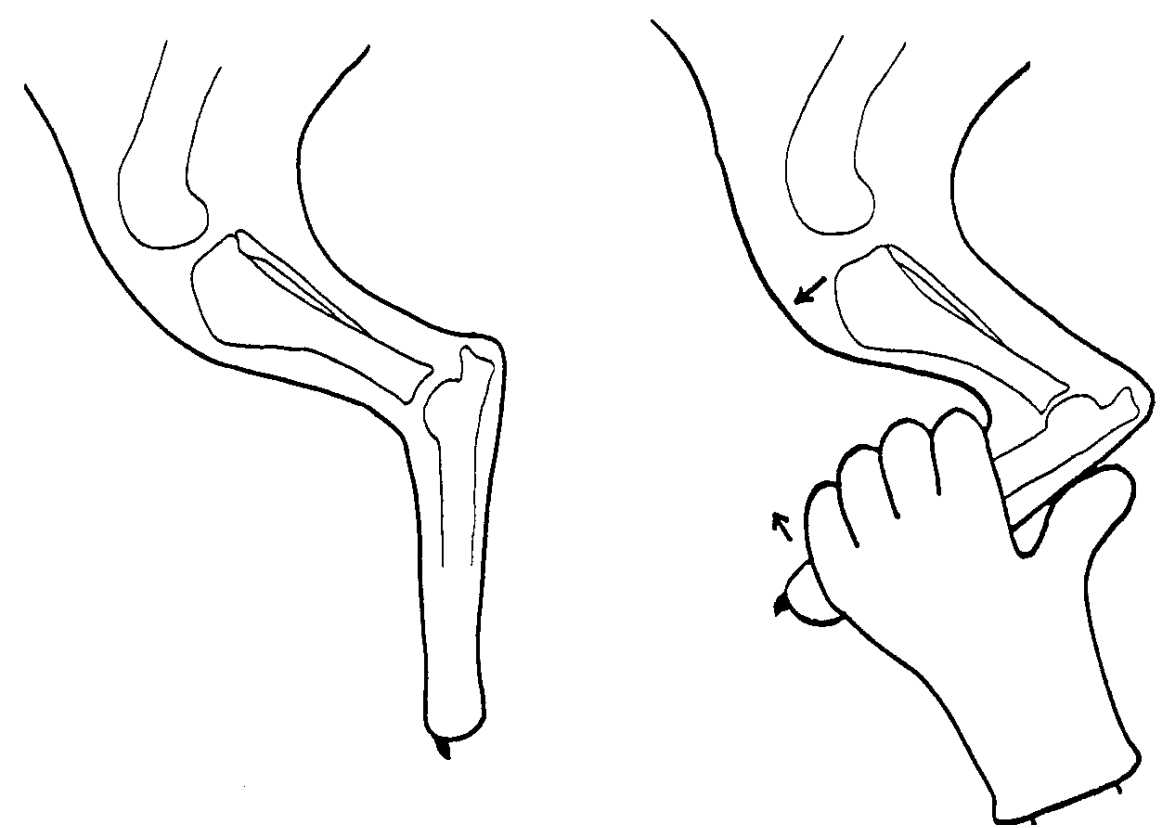

While maintaining the angle of flexion of the stifle joint, the tarsal joint was maximally flexed by use of manual pressure, and a second radiograph was obtained (tibial compression position) (Figure). In the case of a positive tibial compression radiograph, when compared with the neutral view, the proximal tibia will appear too far cranially in relation to the distal femur when stress is applied (Figure). The radiographic test is objective and there is no interposition of soft tissue. Tibial compression radiography is reliable for both complete and partial CCL ruptures, showing a high sensitivity and a hundred per cent specificity (de Rooster et al. 1998; de Rooster \& van Bree 1999b). The location of the sesamoid bone of the popliteal muscle on stress radiographs is also a useful and easy parameter in the interpretation of tibial compression radiographs in cases of CCL rupture in the dog. Distal displacement of the popliteal sesamoid will confirm the presence of CCL rupture (de Rooster \& van Bree 1999a). In a small number of dogs the popliteal sesamoid does not ossify, and therefore remains invisible as a radiographic parameter. A lack of ossification mainly occurs in small breed dogs. In most of those dogs, however, the craniocaudal displacement of the tibia will already be so obvious on the tibial compression radiograph that no additional parameters need to be assessed to come to a definite diagnosis of CCL damage. An accuracy of 99 per cent and a specificity of 100 per cent were achieved by assessing the localisation of the sesamoid bone in the diagnosis of cruciate disease (de Rooster \& van Bree 1999a).

In partial CCL rupture, the cranial drawer test demands a certain portion of the CCL to be torn. All cases of partial rupture in the present study showed a positive tibial compression radiograph (de Rooster \& van Bree 1999b). In contrast with the physical tibial compression test (Henderson \& Milton 1978), the stifle is held at an angle of $90^{\circ}$ while making the tibial compression radiograph. The canine CCL is formed by a craniomedial and a caudolateral bundle; the former is under tension during the whole range of motion of the stifle, while the latter is loose when the joint is flexed (Arnoczky \& Marshall 1977). These features can have an effect in cases of partial rupture of the cranial cruciate. At full extension, a false negative result is likely if only the craniomedial bundle of the ligament has ruptured, because the caudolateral bundle can mask the instability. In flexion, however, the caudal bundle of the cranial cruciate will always be loose, regardless of the state of the cranial bundle. As a result, fewer cases of incomplete damage will be missed when the tibial compression stress is 
exerted on a flexed stifle joint. Differences in degree of damage to the ligament and medial meniscus cannot be deducted from the amount of relative displacement measured on radiographs (de Rooster \& van Bree 1999c).

\section{Discussion}

Tibial compression stress radiography is a valuable asset in the diagnosis of canine stifle instability due to cranial cruciate tearing. It is a useful technique to prove (or disprove) a tentative diagnosis of CCL damage, especially when there is a lack of cranial drawer sign on clinical examination. No false positive results were obtained.

\section{Conclusion}

Tibial compression stress radiography is able to detect complete or partial tears of the CCL. It is an easy and reliable technique which does not require expensive equipment or a high level of technical proficiency.

\section{$\underline{\text { References }}$}

Arnoczky SP, Marshall JL. The cruciate ligaments of the canine stifle: an anatomical and functional analysis. Am J Vet Res 1977;38:1807-1814.

de Rooster H, Van Ryssen B, van Bree H. Diagnosis of cranial cruciate ligament injuries in dogs by tibial compression radiography. Vet Rec 1998;142:366-368.

de Rooster H, van Bree H. Popliteal sesamoid displacement associated with cruciate rupture in the dog. J Small Anim Pract 1999a:40;316-318.

de Rooster H, van Bree H. Use of compression stress radiography for the detection of partial tears of the canine cranial cruciate ligament. J Small Anim Pract 1999b: 40;573-576.

de Rooster H, van Bree H. Radiographic measurement of craniocaudal instability in stifle joints of clinically normal dogs and dogs with injury of a cranial cruciate ligament. Am J Vet Res 1999c:60;1567-1570.

Farrow CS. Stress radiography: Applications in small animal practice. J Am Vet Med Assoc 1982;181:777-784.

Flo GL, DeYoung D. Meniscal injuries and medial meniscectomy in the canine stifle. J Am Anim Hosp Assoc 1978;14:683-689.

Henderson RA, Milton JL. The tibial compression mechanism: a diagnostic aid in stifle injuries. J Am Anim Hosp Assoc 1978;14:474-479.

Jacobsen K. Stress radiographical measurement of the anteroposterior, medial and lateral stability of the knee joint. Acta Orthop Scand 1976;47:335-344.

Kirby BM. Decision-making in cranial cruciate ligament ruptures. Vet Clin North Am:SAP 1993;23:797-819. 
Meinen JJ, Verbeek M. Voorste kruisbandlaesies bij de hond: een evaluatie van therapie, klinisch en röntgenologisch verloop bij 215 patiënten. Referaat.

Geneeskunde van het Kleine Huisdier, Vakgroep Radiologie, Rijksuniversiteit te Utrecht 1980.

Park RD. Radiographic evaluation of the canine stifle joint. Comp Cont Ed 1979;1:833-841.

Pond MJ, Campbell JR. The canine stifle joint. I. Rupture of the anterior cruciate ligament. An assessment of conservative and surgical treatment. J Small Anim Pract 1972;13:1-10.

Robins GM. The canine stifle. The diagnosis and management of acquired abnormalities. In: Whittick WG, ed. Canine Orthopaedics. Philadelpia:Lea and Febiger, 1990;724-752.

Singleton WB. The diagnosis and surgical treatment of some abnormal stifle conditions in the dog. Vet Rec 1957;69:1387-1394. 